\title{
Peri-Operative Management of the Surgical Patient With Diabetes: A Guideline Summary
}

\author{
Leigh White
}

\begin{abstract}
Background: Diabetes significantly increases the risk of morbidity and mortality associated with surgery. These guidelines target anesthetists, providing guidelines for management of the diabetic patients in the pre-operative, peri-operative and post-operative periods.

Methods: The following paper summarizes the Association of Anaesthetists of Great Britain and Ireland clinical guidelines on peri-operative management of the surgical patients with diabetes 2015 .

Results: It is recommended that where possible all diabetic patients achieve an $\mathrm{HbAlc}$ less than $69 \mathrm{mmol} / \mathrm{mol}(8.5 \%)$ prior to surgery. On the day of surgery, fasting periods should be limited to one meal and if this is not possible, a variable-rate intravenous insulin infusion should be started. Intra-operatively blood glucose should remain between 6 and $10 \mathrm{mmol} / \mathrm{L}$. Post-operatively, the key to resuming normal diabetic management is through returning to an normal diet as soon as possible.
\end{abstract}

Conclusions: The aim of management of a diabetic patient during the operative period is to maintain normal blood glucose levels (6 $10 \mathrm{mmol} / \mathrm{L}$ ). This is achieved through careful pre-operative planning, appropriate management of blood glucose levels and fluid balance intra-operatively and a smooth transition to resume the patients normal diabetic management.

Keywords: Diabetes; Peri-operative; Anesthesia

\section{Introduction}

The following paper summarizes the Association of Anaesthetists of Great Britain and Ireland clinical guidelines on perioperative management of the surgical patients with diabetes

Manuscript accepted for publication May 03, 2016

School of Medicine, Faculty of Science, Medicine and Health, University of Wollongong, NSW 2522, Australia; Wagga Wagga Base Hospital, NSW, Australia.Email:1w844@uowmail.edu.au

doi: http://dx.doi.org/10.14740/jem350w
2015 [1]. Diabetes significantly increases the risk of morbidity and mortality associated with surgery. The poor outcomes associated with diabetes is related to hypoglycemia and hyperglycemia, complex polypharmacy, increased infection rates, microvascular and macrovascular co-morbidities and insulin prescribing errors [2-8]. These guidelines target anesthetists, providing guidelines for management of the diabetic patients in the pre-operative, peri-operative and post-operative periods.

\section{Primary Care and Surgical Outpatient Clinic}

It is recommended that all patients undergoing elective surgery should have an HbAlc less than $69 \mathrm{mmol} / \mathrm{mol}(8.5 \%)$. This should be addressed at the time of referral for elective surgery. When assessed in the surgical outpatient clinic, there should be a recorded HbAlc less than $69 \mathrm{mmol} / \mathrm{mol}$ within 3 months leading up to the surgery. If this has not been achieved, then the surgery should be delayed to allow for better control. If this is not achievable such as in the presence of chronic infection or steroid treatment, the surgery should proceed with all risks explained to the patient. The risks include a $50 \%$ increase in mortality and two to three times the risk of surgical site infections, respiratory infections, myocardial infarction and acute kidney injury [2]. In addition to glycemic control, it is important for the outpatient surgical team to have access to information regarding type of diabetes, duration, complications and current management.

\section{Pre-Operative Assessment and Management}

The pre-operative assessment should occur well in advance to 1) optimize glycemic control and 2) ensure all investigations are performed to assess co-morbidities. This recommendation is backed by the National Institute for Health and Care Excellence (NICE) guidance on peri-operative testing [9]. At this time, the patient should be educated on the impact of the preoperative, peri-operative and post-operative periods on glycemic control.

It is recommended that the patient be for day surgery with minimal fasting time, whilst maintaining euglycemia (6 - 10 $\mathrm{mmol} / \mathrm{L}$ ). Pre-operatively if the patient is expected to only miss one meal, this may be facilitated through alterations to 
their current diabetes management. Patients should also be advised to carry a source of glucose during the fasting period and that they are likely to experience erratic glycemic control following the surgery.

During the fasting period, the aim is to avoid hyperglycemia and hypoglycemia. There are specific recommendations for insulin and oral hypoglycemic agents in the context of a short (one meal missed) fasting period. Once daily long acting insulins whether given the night before or on the day of surgery should be reduced by $20 \%$ and blood glucose levels (BGLs) should be checked on admission. If a variable rate intravenous insulin infusion (VRIII) is used, it should continue at $80 \%$ of the patients usual insulin dose. In patients using a twice daily biphasic or short acting insulin, there should be no dose adjustment the day prior to surgery. On the morning of surgery, half the calculated total dose should be given as an intermediate acting insulin. In patients on short acting insulin given three to five times per day, there should be no change in dose the night before. On the morning of surgery, the basal insulin should remain unchanged with bolus insulin omitted. All oral hypoglycemic agents should be taken as normal the night prior to surgery. On the day of surgery, metformin, GLP-1 analogues and pioglitazone should be taken as normal, unless the surgery requires contrast media in the case of metformin. Medications that should be withheld on the day of surgery include sulphonylureas, meglitinides and acarbose. The only medication requiring dose changes is SGLT-2 inhibitors, which are reduced by $50 \%$. If a VRIII is being used all medications should be withheld, with the exception of GLP-1 inhibitors which can be taken as normal. It is recommended that VRIII should be used in patients who miss more than one meal, those with type-1 diabetes, those with poorly controlled diabetes (HbAlc $>69$ $\mathrm{mmol} / \mathrm{mol}$ ) and those that require emergency surgery.

\section{Intra-Operative Care and Monitoring}

It is recommended that BGLs should be measured before and regularly during a surgery aiming for a target range of $6-10 \mathrm{mmol} / \mathrm{L}$. Diabetic ketoacidosis should be treated for if BGLs exceed $12 \mathrm{mmol} / \mathrm{L}$ and blood ketones are greater than 3 $\mathrm{mmol} / \mathrm{L}$ (or urine ketones $>2+$ on dipstick). If hyperglycemia and not DKA is present intra-operatively, the patient should be managed with subcutaneous rapid acting insulin (no more than 6 IU). The BGL should be checked hourly and only given a second dose of insulin after $2 \mathrm{~h}$. Initiation of a VRIII should only be considered in a type- 2 diabetic who remains hyperglycemic. It is recommended that hypoglycemia of $4-6 \mathrm{mmol} / \mathrm{L}$ be treated with $50 \mathrm{~mL}$ of $20 \%$ glucose and if the BGL is $<4$ $\mathrm{mmol} / \mathrm{L}$, then $100 \mathrm{~mL}$ of $20 \%$ glucose should be given.

\section{Fluid Management}

In patients without a VRIII, Hartmann's solution is the fluid of choice to avoid hyperglycemia and hyperchloremic metabolic acidosis. In patients with VRIII, it is recommended that glucose $5 \%$ in saline $0.45 \%$ or potassium $0.3 \%$ be the initial fluid of choice. The rate of infusion should be $25-50 \mathrm{~mL} / \mathrm{kg} /$ day to meet normal maintenance requirement. If non-hypervolemic hyponatremia occurs, the fluid of choice is either glucose 5\% in $0.9 \%$ saline with $0.15 \%$ potassium or glucose $5 \%$ in $0.9 \%$ saline with $0.3 \%$ potassium. The addition of a balanced isotonic solution may be used for optimal fluid balance.

\section{Resuming "Normal" Medication and Diet Post- Operation}

It is recommended that patients with a new or changed intraoperative insulin regiment be consulted on by a specialist diabetes team. Once a normal diet is resumed, oral hypoglycemic agents may be restarted. The exception is metformin, which should be withheld until estimated glomerular filtration rate exceeds $50 \mathrm{~mL} / \mathrm{min} / 1.73 \mathrm{~m}^{2}$. A VRIII in a type- 1 patient needs to continue until 30 - 60 min after the first dose of subcutaneous insulin. Recommencement of subcutaneous insulin may require dose adjustment for food intake, post-operative stress or infection. The restarting of subcutaneous insulin must be prior to a meal.

\section{Other Anesthetic Considerations}

It is recommended that the use of dexamethasone be carefully considered due to the risk of hyperglycemia. If used, BGLs should be measured hourly for $4 \mathrm{~h}$ after administration. The use of regional anesthesia should also be carefully considered, as diabetic patients are at higher risk of developing epidural abscesses, hemodynamic instability (if autonomic neuropathy is present) and post-nerve block neuropathy.

\section{Diabetes and Emergency Surgery}

It is recommended that a VRIII should be used in the setting of an emergency surgery, unless there is concurrent DKA, which would require a fixed rate intravenous insulin infusion. The target BGL range of $6-10 \mathrm{mmol} / \mathrm{L}$ remains the same. Emergency surgery in the context of DKA should be carefully considered and the decision making process should include the anesthetists, surgeons, intensivists and diabetologists. Intraoperatively a fixed rate insulin infusion should be used, and this requires regular blood glucose monitoring and the administration of $20 \%$ glucose if BGLs fall below $14 \mathrm{mmol} / \mathrm{L}$. In addition to the insulin infusion, where possible, long acting insulins should also be continued at $80 \%$ normal dose. The resuscitation fluid of choice is either Hartmann's solution or normal saline with pre-mixed potassium chloride.

\section{Safety}

Insulin is one of the top five high risk medications due to the number of preparations, errors in prescribing and administration. Specifically, VRIIIs are associated with hyperglycemia, 
hypoglycemia, hyponatremia and ketosis on cessation. It is advised that patients on VRIIIs have hourly BGLs and that cessation in type-1 diabetics does not occur without overlapping subcutaneous insulin therapy.

It is recommended that metformin only be withheld preoperatively and peri-operatively if the patient has or is at risk of acute kidney injury. Due to the risk of lactic acidosis metformin should only be resumed once estimated glomerular filtration rate exceeds $50 \mathrm{~mL} / \mathrm{min} / 1.73 \mathrm{~m} 2$.

\section{Conclusions}

The aim of management of a diabetic patient during the operative period is to maintain normal blood glucose levels (6 - $10 \mathrm{mmol} / \mathrm{L}$ ). This is achieved through careful pre-operative planning, appropriate management of blood glucose levels and fluid balance intra-operatively and a smooth transition to resume the patients normal diabetic management.

\section{Conflicts of Interest}

None.

\section{References}

1. Barker P, Creasey PE, Dhatariya K, Levy N, Lipp A, Nathanson $\mathrm{MH}$, Penfold N, et al. Peri-operative management of the surgical patient with diabetes 2015: Association of Anaesthetists of Great Britain and Ireland. Anaesthesia.
2015;70(12):1427-1440.

2. Frisch A, Chandra P, Smiley D, Peng L, Rizzo M, Gatcliffe C, Hudson M, et al. Prevalence and clinical outcome of hyperglycemia in the perioperative period in noncardiac surgery. Diabetes Care. 2010;33(8):1783-1788.

3. Rayman G. Inpatient audit. Diabetes Update. https:// www.diabetes.org.uk/upload/Professionals/publications/Comment_Inpatient\%20audit_new.pdf (accessed 11/08/2015).

4. Hamblin PS, Topliss DJ, Chosich N, Lording DW, Stockigt JR. Deaths associated with diabetic ketoacidosis and hyperosmolar coma. 1973-1988. Med J Aust. 1989;151(8):439, 441-432, 444.

5. Stamler J, Vaccaro O, Neaton JD, Wentworth D. Diabetes, other risk factors, and 12-yr cardiovascular mortality for men screened in the Multiple Risk Factor Intervention Trial. Diabetes Care. 1993;16(2):434-444.

6. National Patient Safety Agency. Insulin safety. Reducing harm associated with the unsafe use of insulin products. http://www.nrls.npsa.nhs.uk/resources/ collections/10-for-2010/insulin/?entryid45=74287 (accessed 06/12/2015).

7. Jhanji S, Thomas B, Ely A, Watson D, Hinds CJ, Pearse RM. Mortality and utilisation of critical care resources amongst high-risk surgical patients in a large NHS trust. Anaesthesia. 2008;63(7):695-700.

8. Pearse RM, Harrison DA, James P, Watson D, Hinds C, Rhodes A, Grounds RM, et al. Identification and characterisation of the high-risk surgical population in the United Kingdom. Crit Care. 2006;10(3):R81.

9. In: Preoperative Tests (Update): Routine Preoperative Tests for Elective Surgery. London, 2016. 